Pacific Journal of Mathematics

A DENSITY THEOREM ON THE NUMBER OF CONJUGACY 


\title{
A DENSITY THEOREM ON THE NUMBER OF CONJUGACY CLASSES IN FINITE GROUPS
}

\author{
EDWARD A. BERTRAM
}

For each finite group $G$ with $k(G)$ conjugacy classes and order $g$, it is well known that $g<2^{2^{k}}$. On the other hand, all groups with a given small $k(\leqq 8)$ have been determined, and these studies, along with the result that if $G$ is nilpotent then $g<2^{k}$, strongly suggest that the bound can be significantly improved. We prove that for each $c_{2}<\log 2$, almost all integers $g \leqq n$, as $n \rightarrow \infty$, have the property that for each $G$ of order $g, k(G)>(\log n)^{c_{2}}$.

The question of whether there exist finite groups $G$ of arbitrarily large order $|G|$ with a fixed number of conjugacy classes $k$ was first asked by Frobenius, and answered in the negative in 1903 by E. Landau [5], using the class equation. In 1919 G. A. Miller [6] discussed a definite upper bound for $|G|$ in terms of $k$; in 1968 P. Erdös and P. Turán [3], and independently M. Newman [8] gave proofs that $k(G)>\log _{2} \log _{2}|G|$, again all using Landau's method. When $G$ is a p-group, P. Hall (unpublished) and later J. Poland [9] had already obtained a parametric equation for $k(G)$, from which it readily follows that if $G$ is nilpotent, then $k(G)>\log _{2}|G|$; however the latter inequality does not hold for all solvable groups. R. Brauer [1, p. 137] has asked for a substantial improvement on the bounds obtained by Landau's method, and our main theorem shows that for "most" group orders there is indeed a substantial improvement:

TheOREM. For each $c_{2}<\log 2$, almost all integers $g \leqq n$, as $n \rightarrow \infty$, have the property that if $G$ is a group of order $g$, then $k(G)>(\log n)^{c_{2}}$.

Thus, if we let $N(n)$ denote the number of integers $g \leqq n$ such that $k(G)>(\log n)^{c_{2}}$ for each group $G$ of order $g$, we will prove that $\lim _{n \rightarrow \infty} N(n) / n=1$.

A cryptic remark by G. A. Miller [7, p. 361, line 21] led us ${ }^{1}$ to the following lemma, which has apparently never been formally stated, but is basic to the entire discussion. Let $d(m)$ denote the number of divisors of $m, G$ a finite group, of order $|G|$, and partitioned into $k(G)$ conjugacy classes; for $p$ a prime $P\left(p^{\prime} ;|G|\right)$ denotes

1 The author would like to thank Professor Robert Gilman for helpful comments here. 
the number of primes $\neq p$ which divide $|G|$ but do not divide $p-1$. For $H$ a subgroup of $G, N(H)$ denotes the normalizer of $H$ in $G$, and $C(H)$ the centralizer, that is $N(H)=\{x \in G \mid x H=H x\}$ and $C(H)=\{x \in G \mid x h=h x$ for all $h \in H\}$. $\langle x\rangle$ denotes the subgroup generated by $x$.

Lemma 1. Suppose $p|| G \mid$. Then $k(G) \geqq \min _{m \mid p-1}\{(p-1) / m+$ $d(m)\}+P\left(p^{\prime} ;|G|\right)$.

Proof. Suppose the prime $p|| G \mid$ and let $x$ be an element in $G$ of order $p$. To see how the elements of $\langle x\rangle$ are partitioned into (parts of the) conjugacy classes of $G$, we examine $N(\langle x\rangle)$ since, for $r, s \not \equiv 0(\bmod p), z^{-1} x^{r} z=x^{s}$ implies $z^{-1}\langle x\rangle z=\langle x\rangle$. Now $C(\langle x\rangle)$ is a normal subgroup of $N(\langle x\rangle)$; let $m$ denote the index of $C(\langle x\rangle)$ in $N(\langle x\rangle)=C(\langle x\rangle) \dot{\cup} C y_{1} \dot{\cup} C y_{2} \dot{\cup} \cdots \dot{\cup} C y_{m-1}$. Then the maximum number of elements in $\langle x\rangle$ which lie in the same conjugacy class in $G$ is $\leqq m$. For if $z^{-1} x^{r} z=x^{s}$, then $z \in N(\langle x\rangle) \Rightarrow z=c$ or $c y_{j}$ for some $c \in C(\langle x\rangle)=$ $C(x)$, and $1 \leqq j \leqq m-1$. Thus we have a mapping from the set of all $x^{r}$ which are conjugate to $x^{s}$ into the set of coset representatives $\left\{e, y_{1}, y_{2}, \cdots, y_{m-1}\right\}$. This mapping is well defined, since if $z_{1}^{-1} x^{r} z_{1}=x^{s}$ and $z_{2}^{-1} x^{r} z_{2}=x^{s}$, then $z_{2}\left(z_{1}^{-1} x^{r} z_{1}\right) z_{2}^{-1}=x^{r} \Rightarrow z_{2} z_{1}^{-1} \in C\left(x^{r}\right) \Rightarrow z_{2} z_{1}^{-1} \in C(x)$, that is $z_{1}$ and $z_{2}$ lie in the same coset of $C(\langle x\rangle)$. The mapping is also one-to-one, since if $z^{-1} x^{r} z=x^{s}=z_{0}^{-1} x^{t} z_{0}$ with $r, s, t \neq \equiv 0(\bmod p)$, then $z=c y_{i}, \quad z_{0}=c_{0} y_{j} \quad$ with $\quad c, c_{0} \in C(x) \Rightarrow y_{i}^{-1} x^{r} y_{i}=y_{i}^{-1}\left(c^{-1} x^{r} c\right) y_{i}=$ $z^{-1} x^{r} z=x^{s}=z_{0}^{-1} x^{t} z_{0}=y_{j}^{-1}\left(c_{0}^{-1} x^{t} c_{0}\right) y_{j}=y_{j}^{-1} x^{t} y_{j}$. Thus $y_{i}=y_{j} \Rightarrow x^{t}=x^{r}$. We have now shown that the elements of $\langle x\rangle$ are partitioned into at least $(p-1) / m+1$ (subsets of) conjugacy classes in $G$, counting the identity class.

Since $N(\langle x\rangle) / C(\langle x\rangle)$ is isomorphic to a subgroup of the cyclic group of automorphisms of $\langle x\rangle$, the factor group is cyclic and generated by $y C(x)$, for some $y \in N(\langle x\rangle)$. Since $N(\langle x\rangle)=\langle C(x),\langle y\rangle\rangle$ we have, either by counting or an Isomorphism Theorem, that

$$
\frac{|\langle y\rangle|}{|C(x) \cap\langle y\rangle|}=\frac{|\langle C(x),\langle y\rangle\rangle|}{|C(x)|}=m .
$$

Hence $m||\langle y\rangle \mid,\langle y\rangle$ has a cyclic subgroup of order $m$, and for each different divisor $l$ of $m$ we have an element of order $l$. Since elements of different orders must lie in different classes of $G$, we have $d(m)-1$ additional conjugacy classes. These have not been counted earlier since each nonidentity element in $\langle x\rangle$ has order $p$, whereas each $l \mid p-1$. Finally, every prime $q \neq p$ such that $q|| G \mid$ and $q \nmid m$ provides at least one new class, and then the same is true for each prime $q \neq p$ such that $q|| G \mid$ and $q \nmid p-1$. We have shown 
that for each prime $p|| G \mid, k(G)$ satisfies $k(G) \geqq(p-1) / m+d(m)+$ $P\left(p^{\prime} ;|G|\right)$ for some $m \mid p-1$. But then $k(G) \geqq \min _{m \mid p-1}\{(p-1) / m+$ $d(m)\}+P\left(p^{\prime} ;|G|\right)$ and the proof of the lemma is complete.

EXAMPLES. $|G|=60 \Rightarrow k(G) \geqq 5 ;|G|=156 \Rightarrow k(G) \geqq 6$.

Let $\nu(n)$ denote the number of distinct prime factors of $n$, and $d(m)$ the total number of divisors of $m ; p_{j}$ is the $j$ th prime.

Lemma 2. (Hardy and Wright, [4, § 18.1]). Given $\varepsilon>0$,

(a) there exists a constant $c(\varepsilon)>1$ such that $d(n)<c(\varepsilon) n^{\varepsilon}$ for all $n \geqq 2$; and

(b) $d(n)<n^{\varepsilon}$ for all sufficiently large $n$.

LEMma 3. Given $\varepsilon>0$, there exists a positive constant $c_{0}(\varepsilon)<1$ such that

$$
\min _{m \mid n}\left\{d(m)+\frac{n}{m}\right\}>c_{0} 2^{(1-c) \nu(n)} \text { for all } n \geqq 2 \text {. }
$$

Furthermore, for sufficiently large $\nu(n)$, this minimum is $>2^{(1-\varepsilon) \nu(n)}$.

Proof. We prove the first part; the second is proved similarly. If $\nu(n / m) \leqq \varepsilon \nu(n)$ then $d(m) \geqq 2^{\nu(m)} \geqq 2^{\nu(n)-\nu(n / m)} \geqq 2^{(1-\varepsilon) \nu(n)}$. If $\nu(n / m)>$ $\varepsilon \nu(n)$, then $d(n / m) \geqq 2^{\nu(n / m)}>2^{\varepsilon \nu(n)}$. But now from (a) of Lemma 2, $c(\varepsilon) \cdot(n / m)^{\varepsilon}>d(n / m)>2^{\varepsilon \nu(n)}$ or $n / m>(1 /(c(\varepsilon)))^{1 / \varepsilon} 2^{\nu(n)}$. Thus the inequality to be proved holds with $c_{0}(\varepsilon)=(1 /(c(\varepsilon)))^{1 / \varepsilon}$. That $1-\varepsilon$ may not be replaced by 1 , no matter how small $c_{0}>0$, is seen by considering the sequence $n=\prod_{j=1}^{l} p_{j}$ as $l \rightarrow \infty$. If we let $m=\prod_{j=l-v+1}^{l} p_{j}$, $v$ to be chosen such that, for example $l-v=[\sqrt{l}]$, then

$$
\min _{m ! n}\left\{d(m)+\frac{n}{m}\right\} \leqq 2^{v}+\prod_{j=1}^{l-v} p_{j}
$$

So

$$
\frac{\min _{m \backslash n}\{d(m)+n / m\}}{2^{\nu(n)}}<\frac{1}{2^{l-v}}+\frac{1}{2^{l-2 p_{l-v}}},
$$

since $\prod_{j=1}^{l-v} p_{j}<4^{p_{l-v}}$. Now $p_{l-v}<3 / 2(l-v) \log (l-v)$, for all large enough $l$, and then $l-2 p_{l-v}>l-3(l-v) \log (l-v)>(2 l) / 3$. Thus $l-v$ and $l-2 p_{l-v}$ each $\rightarrow \infty$, and we are finished.

From Lemmas 1 and 3 follows immediately our first theorem.

TheOREm 1. For each $\varepsilon>0$, there exists a positive constant $c_{0}(\varepsilon)<1$ such that for each prime $p$ dividing $|G|, k(G)>c_{0} 2^{(1-\varepsilon) \cup(p-1)}$.

TheOREM 2. (P. Erdös, [2]). Given an arbitrarily small posi- 
tive $\varepsilon$, then for almost all primes $p \leqq n$, i.e., except for o $(n / \log n)$ of the primes $\leqq n$, as $n \rightarrow \infty$,

$$
(1-\varepsilon) \log \log n<\nu(p-1)<(1+\varepsilon) \log \log n .
$$

Theorem 3. (S. Selberg, [10]). Let $\mathscr{P}$ be a set of primes, $C>0$ and $h \geqq 1$ constants, such that

$$
\sum_{\substack{p \leq n \\ p \in \mathscr{S}}} \frac{1}{p}>\frac{\log \log n}{h}-C .
$$

Then there exists a constant $D$ (depending only on $h$ and $C$ ) such that, if $A(n, \mathscr{P})$ denotes the number of integers $g \leqq n$ and not divisible by any prime in $\mathscr{P}, A(n, \mathscr{P}) / n<D /(\log n)^{1 / h}$.

In particular, if the inequality in the hypothesis can be shown to hold for all $n$ large enough, we may conclude that, as $n \rightarrow \infty$, "almost all" integers $g \leqq n$ are divisible by at least one prime in $\mathscr{P}$. We now state and prove our main theorem:

Theorem 4. For each $c_{2}<\log 2$ almost all integers $g \leqq n$, as $n \rightarrow \infty$, have the property that each group $G$ of order $g$ satisfies $k(G)>(\log n)^{c_{2}}$.

Proof. For each fixed $\varepsilon>0$ we know that for sufficiently large $\nu(p-1)$, if $p|| G \mid$ then $k(G)>2^{(1-\varepsilon / 2) \nu(p-1)}$, by Lemmas 1 and 3. Thus we need only show that, as $n \rightarrow \infty$, almost all $g \leqq n$ are divisible by a prime $p$ satisfying $\nu(p-1)>(1-(1 / 2) \varepsilon) \log \log n$.

For any fixed positive $\varepsilon$, let $\mathscr{P}$ be the set of all primes $p \leqq n$ such that $\nu(p-1)>(1-2 \varepsilon) \log \log n$. Then, if $n^{\prime}+1=$ the least integer $\geqq \exp \left(\log ^{1-\varepsilon} n\right)$ we obtain

$$
\sum_{p \in \mathcal{\infty}} \frac{1}{p} \geqq \sum_{\substack{n, n^{\prime} \\ \nu(p-1) \geq p \leq n \\ \sim(1-8) \log \log p}} \frac{1}{p}
$$

since in the latter sum

$$
\begin{aligned}
(1-\varepsilon) \log \log p & \geqq(1-\varepsilon) \log \log \left(n^{\prime}+1\right) \\
& \geqq(1-\varepsilon)^{2} \log \log n>(1-2 \varepsilon) \log \log n .
\end{aligned}
$$

Let $N(l, \varepsilon)$ denote the cardinality of the collection of all primes $p \leqq l$ such that $\nu(p-1) \geqq(1-\varepsilon) \log \log p$. Then the smaller sum above is

$$
\begin{aligned}
\sum_{n^{\prime}+1 \leqq l \leqq n} \frac{N(l, \varepsilon)-N(l-1, \varepsilon)}{l} & =\sum_{n^{\prime}+1 \leqq l \leqq n} \frac{N(l, \varepsilon)}{l}-\sum_{n^{\prime} \leqq l<n} \frac{N(l, \varepsilon)}{l+1} \\
& >\sum_{n^{\prime}+1 \leqq l<n} \frac{N(l, \varepsilon)}{l(l+1)}-1 .
\end{aligned}
$$


Now by the theorem of Erdös, for each $l>l_{0}(\varepsilon), N(l, \varepsilon)>(3 / 4) l / \log l$. Hence for all $n$ (and thus $n^{\prime}$ and $l$ ) large enough, we find that $(l /(l+1))>2 / 3$ and $)$

$$
\begin{aligned}
\sum_{n^{\prime}+1 \leq l<n} \frac{N(l, \varepsilon)}{l(l+1)} & >\frac{3}{4} \sum_{l=n^{\prime}+1}^{n-1} \frac{1}{(l+1) \log l} \\
& >\frac{1}{2} \int_{n^{\prime}+1}^{n} \frac{d t}{t \log t}=\frac{\varepsilon}{2} \log \log n .
\end{aligned}
$$

Now that $\sum_{p \in \infty} 1 / p>\frac{\varepsilon}{2} \log \log n-1$, for sufficiently large $n$, we may apply Selberg's theorem to our $\mathscr{P}$, obtaining the conclusion desired.

Finally, the author acknowledges with gratitude the comments of Professor Patrick X. Gallagher, which resulted in this improvement of the original theorem, announced in the Notices of the A.M.S., August, 1974.

\section{REFERENCES}

1. R. Brauer, Representations of Finite Groups, in Lectures on Modern Mathematics, ed. T. L. Saaty, Vol. 1, Wiley, New York, 1963.

2. P. Erdös, On the normal number of prime factors of $p-1$ and some related problems concerning Euler's, $\phi$-function, Quart. J. Math., Oxford Series, 6 (1935), 205-213.

3. P. Erdös and P. Turán, On some problems of a statistical group theory IV, Acta Math. Acad. Sci. Hung., 19 (1968), 413-435.

4. G. H. Hardy and E. M. Wright, An Introduction to the Theory of Numbers, Oxford University Press, 4th edition, 1960.

5. E. Landau, Klassenzahl binärer quadratischer Formen von negativer Discriminante, Math. Annalen, 56 (1903), 674-678.

6. G. A. Miller, Groups possessing a small number of sets of conjugate operators, Trans. Amer. Math. Soc., 20 (1919), 260-270.

7. - Groups involving a small number of sets of conjugaie operators, Proc. Nat. Acad. Sci., 30 (1944), 359-362.

8. M. Newman, A bound for the number of conjugacy classes in a group, J. London Math. Soc., 43 (1968), 108-110.

9. J. Poland, Two problems on finite groups with $k$ conjugacy classes, J. Austral. Math. Soc., 8 (1968), 49-55.

10. S. Selberg, A theorem in analytic number theory, Norske Vid. Selsk. Forh., 23 (1951), 1-2.

Received May 22, 1974 and in revised form November 26, 1974.

UNIVERSITY OF HAWAII

AND

University of CALifornia, Los ANGeles 



\section{PACIFIC JOURNAL OF MATHEMATICS}

\section{EDITORS}

RICHARD ARENS (Managing Editor)

University of California

Los Angeles, California 90024

\section{R. A. Beaumont \\ University of Washington \\ Seattle, Washington 98105}

\section{J. DugundJI}

Department of Mathematics

University of Southern California

Los Angeles, California 90007

D. Gilbarg and J. Milgram

Stanford University

Stanford, California 94305

\section{ASSOCIATE EDITORS}
E. F. BECKENBACH
B. H. NeumanN
F. WOLF
K. YOSHIDA

\section{SUPPORTING INSTITUTIONS}

UNIVERSITY OF BRITISH COLUMBIA
CALIFORNIA INSTITUTE OF TECHNOLOGY
UNIVERSITY OF CALIFORNIA
MONTANA STATE UNIVERSITY
UNIVERSITY OF NEVADA
NEW MEXICO STATE UNIVERSITY
OREGON STATE UNIVERSITY
UNIVERSITY OF OREGON
OSAKA UNIVERSITY

UNIVERSITY OF BRITISH COLUMBIA

UNIVERSITY OF CALIFORNIA

MONTANA STATE UNIVERSITY

NEW MEXICO STATE UNIVERSITY

OREGON STATE UNIVERSITY

OSAKA UNIVERSITY

\author{
UNIVERSITY OF SOUTHERN CALIFORNIA \\ STANFORD UNIVERSITY \\ UNIVERSITY OF TOKYO \\ UNIVERSITY OF UTAH \\ WASHINGTON STATE UNIVERSITY \\ UNIVERSITY OF WASHINGTON \\ AMERICAN MATHEMATICAL SOCIETY \\ NAVAL WEAPONS CENTER
}

The Supporting Institutions listed above contribute to the cost of publication of this Journal, but they are not owners or publishers and have no responsibility for its content or policies.

Mathematical papers intended for publication in the Pacific Journal of Mathematics should be in typed form or offset-reproduced, (not dittoed), double spaced with large margins. Underline Greek letters in red, German in green, and script in blue. The first paragraph or two must be capable of being used separately as a synopsis of the entire paper. Items of the bibliography should not be cited there unless absolutely necessary, in which case they must be identified by author and Journal, rather than by item number. Manuscripts, in triplicate, may be sent to any one of the editors. Please classify according to the scheme of Math. Reviews, Index to Vol. 39. All other communications should be addressed to the managing editor, or Elaine Barth, University of California, Los Angeles, California, 90024.

The Pacific Journal of Mathematics expects the author's institution to pay page charges, and reserves the right to delay publication for nonpayment of charges in case of financial emergency.

100 reprints are provided free for each article, only if page charges have been substantially paid. Additional copies may be obtained at cost in multiples of 50 .

The Pacific Journal of Mathematics is issued monthly as of January 1966. Regular subscription rate: $\$ 72.00$ a year (6 Vols., 12 issues). Special rate: $\$ 36.00$ a year to individual members of supporting institutions.

Subscriptions, orders for back numbers, and changes of address should be sent to Pacific Journal of Mathematics, 103 Highland Boulevard, Berkeley, California, 94708.

PUBLISHED BY PACIFIC JOURNAL OF MATHEMATICS, A NON-PROFIT CORPORATION

Printed at Kokusai Bunken Insatsusha (International Academic Printing Co., Ltd.), 270, 3-chome Totsuka-cho, Shinjuku-ku, Tokyo 160, Japan.

Copyright (C) 1973 by Pacific Journal of Mathematics Manufactured and first issued in Japan 


\section{Pacific Journal of Mathematics \\ Vol. 55, No. $2 \quad$ October, 1974}

Walter Allegretto, On the equivalence of two types of oscillation for elliptic

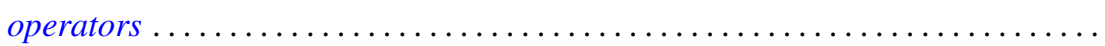

Edward Arthur Bertram, A density theorem on the number of conjugacy classes in

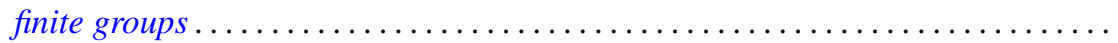

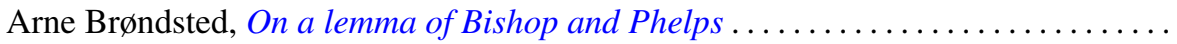

Jacob Burbea, Total positivity and reproducing kernels ..................

Ed Dubinsky, Linear Pincherle sequences . . . . . . . . . . . . . . . . . .

Benny Dan Evans, Cyclic amalgamations of residually finite groups .............

361

Barry J. Gardner and Patrick Noble Stewart, A "going down" theorem for certain

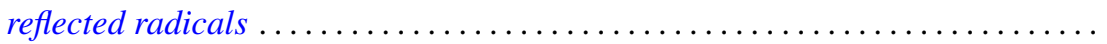

381

Jonathan Light Gross and Thomas William Tucker, Quotients of complete graphs:

revisiting the Heawood map-coloring problem ....................

Sav Roman Harasymiv, Groups of matrices acting on distribution spaces .........

Robert Winship Heath and David John Lutzer, Dugundji extension theorems for

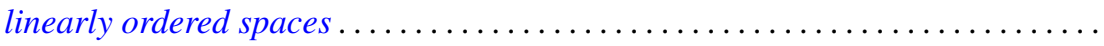

Chung-Wu Ho, Deforming p. l. homeomorphisms on a convex polygonal

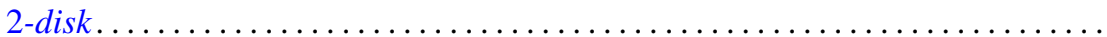

Richard Earl Hodel, Metrizability of topological spaces .................

Wilfried Imrich and Mark E. Watkins, On graphical regular representations of

cyclic extensions of groups .......................... 461

Jozef Krasinkiewicz, Remark on mappings not raising dimension of curves ..... . 479

Melven Robert Krom, Infinite games and special Baire space extensions . . . . . . 483

S. Leela, Stability of measure differential equations . . . . . . . . . . . . . . . . 489

M. H. Lim, Linear transformations on symmetric spaces . . . . . . . . . . . . . . . 499

Teng-Sun Liu, Arnoud C. M. van Rooij and Ju-Kwei Wang, On some group algebra modules related to Wiener's algebra $M_{1} \ldots \ldots \ldots \ldots \ldots \ldots \ldots \ldots \ldots \ldots \ldots$

Dale Wayne Myers, The back-and-forth isomorphism construction ............ 521

Donovan Harold Van Osdol, Extensions of sheaves of commutative algebras by

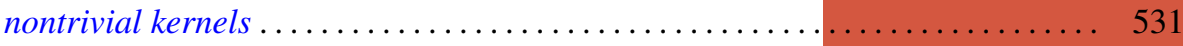

Alan Rahilly, Generalized Hall planes of even order ................... 543

Joylyn Newberry Reed, On completeness and semicompleteness of first countable

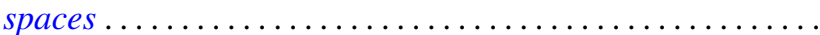

Alan Schwartz, Generalized convolutions and positive definite functions associated

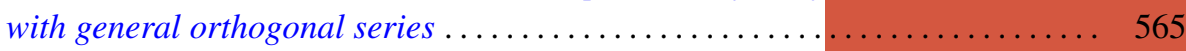

Thomas Jerome Scott, Monotonic permutations of chains . . . . . . . . . . . 583

Eivind Stensholt, An application of Steinberg's construction of twisted groups .... 595

Yasuji Takeuchi, On strongly radicial extensions . . . . ................. 619

William P. Ziemer, Some remarks on harmonic measure in space . . . . . . . . . . 629

John Grant, Corrections to: “Automorphisms definable by formulas” . . . . . . . . 639

Peter Michael Rosenthal, Corrections to: "On an inversion for the general

Mehler-Fock transform pair" ......................... 640

Carl Clifton Faith, Corrections to: "When are proper cyclics injective” . . . . . . 640 